\title{
CIBERACTIVISMO, ACCIÓN COLECTIVA Y MOVILIDAD EN BICICLETA. Una etnografía virtual en Quito
}

\author{
Andrés RODRÍGUEZ MERA \\ Flacso Sede Ecuador \\ andresrodriguezfm@live.com
}

\section{CIBERACTIVISM, COLLECTIVE ACTION, AND BIKE MOBILITY. A virtual ethnography at Quito}

Resumen: En esta investigación el objetivo principal fue comprender los procesos de acción colectiva que se generan en una agrupación de ciclistas de Quito dentro una red de comunicación mediada por la tecnología. La propuesta metodológica se basa en un enfoque mixto: cuantitativo y cualitativo. Analizamos los eventos publicados en la página de Facebook de Cleta Endiablada durante el mes de abril de 2016, como prácticas digitales que presentan contenidos textuales, fotográficos, y audiovisuales. Sostenemos que la acción colectiva es una forma de interacción y comunicación. La página del colectivo de ciclistas se convierte en un espacio digital donde los ciclistas urbanos comunican al sistema social las acciones de su inconformidad, desacuerdos y disputas políticas. Se identifica que el uso de la página de Facebook es una interacción mediada por el activismo político, identificación y discurso social que caracteriza al colectivo de ciclistas. Este texto evidencia que el uso de esta red social por parte de la agrupación también es una herramienta virtual para organizar y difundir el discurso dominante de la agrupación: la legalización del consumo de marihuana.

Abstract: At this research the main objective was to understand the collective action process that one biker group in Quito generates within one media social network. The methodological proposition be based on a combined approximation: quantitave and qualitative. We analyze the published events at Cleta Endiablada Fan page over April 2016, such as digitals practices that displays textual, photographic and audiovisual contents. We maintain that collective action is an interaction and communication way. The biker group fan page turns into a digital space where the urban bikers convey to the social system the actions about their unconformity, disagreements and political disputes. We identify a use of the fan page like an interaction interposed by political activism, social identification and speech that characterise the biker group. This text highlights the use of Facebook on the part of the biker group also as well as a virtual tool to arrange and spread the pervasive speech of the organization: the weed consumption legalization.

Palabras clave: Acción colectiva. Ciberactivismo. Colectivos de ciclistas. Consumo de marihuana. Quito Collective action. Ciberactivism. Bikers groups. Weed consumption 


\section{Introducción}

Los activistas de la bicicleta buscan que los actores sociales convivan en una ciudad donde la movilidad en bicicleta deje de ser una expresión minúscula de transportación. El camino de este activismo transita entre manifestaciones y protestas individuales que formulan exigencias políticas y culturales para promover el uso de la bicicleta como una alternativa colectiva de movilidad urbana. Mediante dicha propuesta que promueve el uso de este medio de transporte no motorizado también se defiende el consumo de marihuana, y la ocupación del espacio público.

En este artículo se investiga a los integrantes del colectivo de ciclistas de Quito, Cleta Endiablada (en adelante $\mathrm{CE}$ ), quienes postulan que una de las soluciones a la problemática del sistema de transporte puede ser la reconfiguración de la ciudad como un espacio propicio para la movilidad de la bicicleta. Además, se describe a la red social digital Facebook como un espacio de comunicación donde transitan interacciones y protestas que buscan cambios en la realidad social del ciclismo urbano.

En este contexto, buscamos resolver las siguientes interrogantes: ¿Podemos dialogar sobre ciberactivismo desde acción colectiva de Cleta Endiablada?, ¿Por qué?, ¿Qué es lo que une al colectivo de ciclistas? ¿Cuáles son los conflictos sociales centrales para el colectivo en estudio? La protesta de varias agrupaciones humanas puede traducirse en acción colectiva. Una constitución virtual de los implicados en la movilización permite la vinculación de sus integrantes. Los sujetos se relacionan entre ellos durante la búsqueda y consecución de un objetivo común.

Bajo esta perspectiva, en los tres primeros subacápites concretamos teóricamente las relaciones entre ciberactivismo y acción colectiva para comprender las publicaciones de la página de Facebook de CE como un proceso local de comunicación desde el activismo que promueve la movilidad en bicicleta en Quito. A continuación, describimos los datos y hallazgos sobre las entrevistas, y grupo focal realizados a integrantes de CE, así como, sobre el análisis de contenido de la página de Facebook. Finalmente, en el quinto subacápite, expresaremos las denominaciones y significantes que los activistas de la bicicleta emplean para referirse a los horizontes de sentido sobre la realidad social que desean transformar. A modo de conclusión, explicaremos cómo sus dos principales discursos dominantes: apropiación del espacio público mediante la movilidad en bicicleta y legalización del consumo de marihuana se consolidan a través de redes de amistad y trabajo para fortalecer los procesos de intervención en el ciber espacio.

\section{El ciclismo urbano como acción colectiva en Facebook ${ }^{1}$}

El debate sobre el uso de la bicicleta en Quito recorre experiencias y acciones colectivas con la finalidad de esclarecer las realidades sociales donde participan e interactúan ciclistas que pertenecen a diversos contextos económicos y culturales. Los procesos que caracterizan la primera década del activismo de la bicicleta quiteño (1997-2006) transitan de acciones agitadoras a formas de organización con estructuras administrativas y empresariales, que buscan generar influencia en el poder político pero mediante la conformación de pequeños círculos de poder desde los que pueden acceder a dialogar y colaborar con las instituciones públicas y seccionales. La segunda década (2007-2017) del activismo de la bicicleta en Quito se caracteriza por presentar grupos activistas a favor de la bicicleta que buscan espacios para articular acciones colectivas, desde la denuncia y protesta social, y menos orientados al consenso político.

Uno de estos colectivos de ciclistas de Quito es Cleta Endiablada. Según el registro de su historia que consta como información de la página de Facebook del colectivo sus integrantes se autodefinen: "No somos solo ciclistas sino activistas de la bici, promovemos el uso de la bici como alternativa a la Movilidad que cada vez empeora más. Brindamos información sobre todo lo relacionado a ciclismo urbano. Te asesoramos para armarte tu propia cleta ${ }^{2}$ urbana". Si hablamos de contenidos que se publican a través de redes sociales asistimos a una aproximación comunicacional donde se contempla el rol instrumental del Internet. Situación habitual en nuestras sociedades.

Los actores sociales discuten y debaten en las redes sociales. Una de las primeras iniciativas colectivas que también incide de manera virtual es la protesta contra la Organización Mundial del Comercio. Durante su reunión en Seattle en 1999, fue la primera gran ocasión en la que se hizo visible cómo un movimiento se puede alimentar, propagar y llegar a ser global a través de las -nuevas entonces- tecnologías de la comunicación. (Quintana y Tascón 2012, 10)

\footnotetext{
1 Este artículo de investigación académica hace parte de la investigación "Acción colectiva y redes de comunicación: uso del Facebook en los colectivos ciclistas de Quito”, realizada entre abril a julio de 2017 para optar al título de Magíster en Comunicación y Opinión Pública de Flacso Sede Ecuador..

2 Cleta es la definición coloquial para referirse de manera afectiva a la bicicleta.
} 
Para que el ciclismo urbano concrete sus acciones colectivas, las organizaciones estrechan a sus integrantes, y comparten discursos e identificaciones. De este modo, quienes participan reciben respaldo para el cambio social que persiguen. Esta problemática se aplica a los grupos en los que no es tan relevante la aportación individual como para afectar el resultado final de una empresa colectiva. (Diani y Della Porta $2015,138)$ En nuestro caso de estudio, dicha reflexión tiene vigencia, pues en un colectivo que lo conforman dos mujeres y siete hombres, la confianza se mantiene debido a la preservación de amistad entre los integrantes.

La acción colectiva es un proceso que se desarrolla a lo largo del tiempo, sobre todo respecto al logro de metas. Es difícil, aunque no imposible, determinar los costes y beneficios adecuadamente. Contamos con la certeza del compromiso y de la aceptación del riesgo a corto plazo; pero también, con lo desconocido de los resultados, que no sólo son difíciles de calcular desde el punto de vista del individuo, sino cuyo alcance parece asimismo remotamente prospectivo. (Diani y Della Porta 2015, 139)

La identidad del ciclismo urbano se desarrolla por medio de la transmisión de posturas, actitudes, y esquemas de acción que buscan potenciar la confianza en la identidad del grupo. Es inconcebible transferir motivaciones, métodos y estímulos a otros sujetos si uno mismo no posee convicción y seguridad de la acción que emprende para militar en una organización. Resulta relevante, además, tener presente características del proceso político que pueden influir en las definiciones de identidad. (Diani y Della Porta 2015, 151)

El interés de relacionarse con otros sujetos, establece en el activista político, la habilidad de presentarse como un actor social que manifiesta su predisposición de participación e interacción. El ingreso a un grupo activista es una oportunidad para compartir problemáticas que aluden al plano personal y comunicarlas a una agrupación social que del mismo modo, percibe dichos problemas como un peligro por combatir. A través de Internet, de diversos tipos de redes sociales y de medios de comunicación personales, los individuos y los grupos han adquirido una capacidad de "crear noticias" que supera con creces la que tienen los medios impresos y audiovisuales tradicionales para configurar la acción colectiva. (Tarrow 2012, 73)

Los activistas de la movilidad en bicicleta consideran que la acción colectiva podría resultar eficaz y que ellos mismos son quienes deben organizar la lucha contra los opositores para la consecución y cumplimiento de sus objetivos. Los movimientos -y en concreto las olas de movimientos, que son los principales catalizadores del cambio social- no pueden desligarse de las luchas nacionales por el poder. (Tarrow 2012, 77)

La acción colectiva alcanza difusión cuando las condiciones políticas son favorables y se desarrolla hasta que el sistema político la visibiliza. Las redes virtuales cambian los modos de ver y leer, las formas de reunirse, de hablar y escribir, de amar y saberse amados a distancia, o acaso imaginarlo. Otras formas de ser sociedad y de hacer política emergen en las "movilizaciones relámpago" o flashmobs (Rheingold 2005). Convocadas por correo electrónico o por móviles, reivindicaciones desoídas por organismos internacionales, gobiernos y partidos políticos logran coordinación y elocuencia fuera de los medios. (García Canclini 2007, 78)

Dentro de la dinámica del activismo de la bicicleta en Quito identificamos varias agrupaciones de ciclistas locales e internacionales, empresas del sector privado, fundaciones internacionales, medios de comunicación digital, grupos políticos, Secretarías de la Administración Metropolitana de Quito, autoridades del sector público e inclusive; investigadoras sociales que integran y orientan la acción colectiva que promueve la movilidad en bicicleta [...] últimamente las bicis están por todas partes, y no hace falta estar escribiendo un libro sobre bicis para darse cuenta de ello. Las revistas de tendencias y los suplementos dominicales hacen un reportaje sobre el boom de la bicicleta un número sí y uno no. Las marcas de moda ponen a sus modelos a posar a la vera de algún velocípedo vintage. Cada vez más anuncios tienen una bicicleta como estrella invitada, incluso aunque vendan coches. Definitivamente, la bici está de moda. (Bravo 2014, 50-51)

La defensa de la movilidad en bicicleta conlleva propuestas creativas y lúdicas que condensan ideas de colectivos sociales como CE. Procesos de acción colectiva que provienen de los actores del ciclismo urbano. De quienes se movilizan en bicicleta de forma cotidiana. Los que administran mi ciudad, por mucho que ahora propongan ciclocarriles y servicios de alquiler de bicicletas, no tienen pinta de querer ni de saber de otra movilidad que no sea la del coche oficial. Y tampoco les interesa mucho el resto de lo que hace a una ciudad habitable y acogedora. (Bravo 2014, 160)

La red social más usada en Ecuador es Facebook que registra 9,1 millones de usuarios. Seguida por Instagram, con 1,7 millones y Twitter con 868 mil usuarios. Esto quiere decir que más de la mitad de ecuatorianos tiene una cuenta en alguna red social. ${ }^{3}$ Dicha red social es una oportunidad que bajo determinadas circunstancias sociales y mediante el uso responsable de la información puede comunicar acontecimientos que el sistema mediático olvida o considera irrelevantes dentro de sus agendas temáticas.

En nuestro país, Facebook en 2005, se volvió un fenómeno, los actores sociales pudieron conectarse con

3 "Las Redes Sociales en Ecuador", Cápsula del programa televisivo Políticamente Correcto, 3:00, Ecuavisa, publicado por Claudia Roura 18 de junio de 2017. http://bit.ly/2fdjnXQ 
personas y movimientos sociales que trasladaron luchas sociales al campo virtual. Es decir, Facebook logró reflejar las sociedades existentes, ya que se construyen grupos por estatus social en algunos países, grupos políticos en otros, grupos en defensa y en contra de las organizaciones GLBT, de los colectivos de mujeres o culturales de jóvenes. (Ciespal 2010, 26)

\section{II. ¿Activismo colectivo o ciclismo colectivo?}

El ciberespacio es un sitio determinado para utilizar las infraestructuras tecnológicas existentes. Es un tipo particular de relación entre usuarios de Internet, un verdadero movimiento social que se ha desarrollado sin dependencia económica ni política de Estados y corporaciones internacionales. Los formatos digitales de las redes sociales alcanzan interés y atención pública de forma instantánea. Incluso, anuncian hechos y eventos mucho antes que cualquier medio de comunicación tradicional.

La red social Facebook constituye usuarios activos que aceptan el control y regulación de su información virtual mediante los filtros de seguridad y configuración de la privacidad que condicionan, y a la vez, facultan su existencia e identidad en el ciberespacio. La historia del activismo en Internet es un relato cronológico. Es un proceso cíclico, sin plan, sin líderes, sin producto final: no tiene ni principio ni fin, siempre tiene un medio por el que crece y se desborda. Los hechos que relatamos no son episodios aislados. Tampoco etapas. Son acontecimientos conectados en los que se ha ido tejiendo una red, física pero también de valores y conceptos. (Quintana y Tascón 2012, 122)

Facebook es la red social que mayor importancia recibe por parte de los usuarios de Internet en Ecuador. Por tanto, es importante recordar que conforme al último estudio publicado por el Instituto Nacional de estadística y Censo (INEC 2016), la evolución en la conectividad del país presenta que alrededor de tres de cada diez hogares tiene una computadora de escritorio o portátil. Y nueve de cada diez tienen un teléfono celular. Este creciente uso de la tecnología digital está propiciando la emergencia de nuevos conceptos para definir a esta generación de jóvenes, tales como "Generación Digital" (Mehlman, 2003), "Generación Nintendo" (Beck y Wide, 2006) o "Cyberkids" (Holloway y Valentine, 2003). Estos jóvenes consideran a las nuevas tecnologías como algo propio que les acerca a los otros y, en consecuencia, se apropian de ellas a través del uso cotidiano, que mayoritariamente es de ocio. (Martín 2013, 54)

Respecto a las conclusiones del estudio que realizan Sánchez Burón y Fernández Martín (2010) citado por Adolfo Álvaro Martín (Martín 2013, 65-69) resaltamos que:

en cuanto a la frecuencia de uso de las redes sociales, un 39\% de los adolescentes reconocen utilizarla "varias veces al día”. Las chicas acceden a las redes con más frecuencia que los chicos.

la elevada utilización de las redes sociales en todos los países analizados, siendo Ecuador donde el uso es más intensivo (94,3\%) y España donde su uso es menor $(79,4 \%)$, pese a su incremento en más de un punto respecto año estudio del año anterior.

en la mayoría de países la red social favorita es Facebook, con la excepción de España donde Tuenti es la red favorita de los adolescentes.

se confirma la tendencia que la principal motivación para el uso de las redes sociales es mantener contacto con aquellas personas que ven habitualmente, seguida por el deseo de mantener relación con personas a las que no ven de manera habitual.

El alcance de la acción colectiva de CE que surge de las redes digitales puede iniciar cambios temporales en el ejercicio de políticas públicas y en el poder político dominante. Las organizaciones formales surgen y desaparecen de forma cíclica en función de las olas de acción colectiva de cuyo entusiasmo son reflejo. Ya sean formales o informales, centralizadas o descentralizadas, estas organizaciones se basan en redes de activistas que transforman su amistad, su confianza interpersonal y sus percepciones compartidas en acciones y programas del movimiento. Mediante la utilización de redes sociales existentes, las organizaciones de los movimientos sociales pueden movilizar rápidamente a sus seguidores y presionar a sus adversarios a través de las instituciones establecidas. (Tarrow 2012, 233-234)

Los espacios digitales, comunidades virtuales, y redes sociales legitiman las diversas formas de aprendizaje y participación que realizan usuarios de Internet o cibernautas; actores políticos que desde el análisis de nuestra investigación los observamos como ciberactivistas. Bennet ha argumentado convincentemente que los medios digitales están transformando la naturaleza del activismo de múltiples formas, incluyendo la ampliación de la escala de las redes sociales al ámbito transnacional; la disminución de la importancia relativa de las organizaciones locales y nacionales "off-line" como base del activismo; las mayores ventajas de las organizaciones con pocos recursos dentro de movimientos generales; la mayor facilidad para vincular objetivos específicos de lugares lejanos con campañas en curso, y la utilización conjunta de interacciones cara a cara con relaciones virtuales. (Tarrow 2012, 245)

CE señala que mientras seguía llegando más gente se vio la necesidad de empezar a activar la bicicleta como un ente social, más que como un simple deporte. La bicicleta fue creada para transportarse, para mo- 
verse. Este artículo analiza al colectivo de ciclistas como una organización que genera discursos y prácticas críticas ante la sociedad quiteña. Por ello, resaltamos que la mayoría de investigaciones hechas en el campo de los movimientos sociales y las Tecnologías de la Información y la Comunicación (TIC) [...] tienden a generar perspectivas deterministas y simplistas del papel y la influencia de las TIC en los movimientos sociales, o tienden a opacar el impacto de las acciones colectivas o la influencia que las tecnologías tienen en los procesos políticos, en un sentido amplio de estos. (Barón Porras 2017, 103-126)

CE se caracteriza por ser una agrupación inclusiva respecto a parámetros de edad, y de género. Sus integrantes comentan que incluyen a la mayor cantidad de gente. También se ha diferenciado de otros colectivos de ciclistas quiteños por generar talleres. Espacios de socialización donde se enseña a armar y desarmar una bicicleta. En Ecuador, espacios similares para la expresión y participación sociopolítica de la juventud ya forman parte de anteriores estudios académicos. Las primeras organizaciones juveniles ecuatorianas en la Web 2.0 fueron Diabluma, autodefinida como organización político-cultural, contaba con el $60 \%$ de mujeres entre sus integrantes; y la Coordinadora Política Juvenil por la Equidad de Género (CPJ), identificada como organización feminista de jóvenes mujeres y hombres, que promueven la construcción de un futuro de inclusión en equidad. Estas organizaciones se caracterizan también por su activismo en Internet. Según datos del Instituto Nacional de Estadísticas y Censos (INEC), en un estudio del 2009, solo el 34\% de la población nacional en el área urbana y 9\% en el área rural han utilizado alguna vez el Internet. (Ciespal 2010, 67)

Los sujetos sociales despliegan prácticas, acciones y usos sociales en Internet. De este modo, comprendemos la extensión de las redes mediadas por la tecnología de la comunicación para investigar la interacción entre tecnología y sociedad en el mundo. A través de Facebook, los participantes de las organizaciones sociales han creado un espacio alternativo en donde la información no solo se produce y circula colectivamente sino que también se discute y valida de manera conjunta. La información "legitimada" a través de las interacciones en Facebook se ha convertido en un capital social que los miembros de las organizaciones pueden transformar e intercambiar en otros escenarios sociopolíticos. (Barón Porras 2017, 103-126) En el año 2012, Facebook ronda los 1.000 millones de usuarios registrados, un 85 por ciento de ellos activos (publican en su muro o comparten y valoran otros contenidos a través de los botones "me gusta"), según los datos de la compañía. (Quintana y Tascón 2012, 214-215)

La acción colectiva y el activismo político mediados por la tecnología de comunicación presentan diferentes formatos de difusión, publicación, e interacción de la acción colectiva tradicional. A su vez, las redes sociales son plataformas que facilitan el intercambio de información, la interacción-participación y la colaboración entre usuarios, y pueden generar y estructurar procesos de enseñanza y aprendizaje colaborativos. Constituyen un fenómeno global que va mucho más allá de anécdotas o modas. (Pérez Rubio 2015)

La acción colectiva es un modo de aprendizaje social, en el cual los grupos de actores sociales confirman la viabilidad de diversas formas de disputa y confrontación ante el poder establecido. Earl y Kimport (2011) señalan que las TIC están desafiando la comprensión del qué es una acción colectiva, cuando los esfuerzos se pueden aunar por fuera de lo que se conoce convencionalmente. De manera particular, mencionan tres tipos de cambios: a) la copresencia en el espacio y en el tiempo de la participación colectiva; b) las características efímeras, esporádicas, circunstanciales o perdurables de la acción contenciosa; y c) la evidencia de la existencia de retos y opositores sin movimientos. (Barón Porras 2017, 103-126)

\section{Cleta Endiablada y sus Cicleadas de velocidad}

La perspectiva metodológica para realizar la investigación de campo es mixta. La técnica cuantitativa específica que nos permite aproximarnos científicamente al objeto en estudio es el análisis de contenido de la página de Facebook de CE. Realizamos el seguimiento de la página de Facebook en mención durante el mes de abril del año 2017. La selección de este corpus se justifica mediante la ubicación de un hito que se relaciona con el objetivo de la investigación así como, con las acciones colectivas que promueven CE durante el lapso de análisis. El hito es la Conmemoración del Día Mundial de la Bicicleta que se festeja el 19 de abril. CE mantiene activa su página desde el año 2014. Año en el que se forma el colectivo y desde el que existen dos grupos de Facebook vinculados con la agrupación y vigentes hasta el cierre de nuestra investigación de campo: Cleta Endiablada Actividades y Más, y CletaEndiabladaIntegrantes.

Por medio de tres técnicas de índole cualitativa-observación no participante, aplicación de cuestionarios de entrevistas y realización de un grupo focal- de índole nos aproximaremos a las y los activistas de CE. La investigación cualitativa nos permite comprender los procesos de comunicación que se analizan durante este proceso de estudio. El número de entrevistados no se establece con anterioridad a la elaboración de los cuestionarios de entrevistas. Se presencia asambleas de CE (fecha de reunión 28 de abril de 2017), para conocer el número actual de integrantes activos en cada colectivo. A su vez, la realización del grupo focal que 
reúne a integrantes de Carishina En Bici (colectivo quiteño de mujeres que enseñan a pedalear a mujeres) y Cleta Endiablada es una propuesta arriesgada y se realiza por primera vez en Quito. Entre integrantes de los dos colectivos existe un reconocimiento superficial de las identidades del otro, sin embargo, jamás han compartido un espacio para dialogar y conocer a profundidad el pensamiento y proyectos de sus colegas activistas de la bicicleta.

Respecto al análisis de contenido de la página de Facebook de CE, el corpus de análisis se construye de acuerdo a los siguientes criterios de selección: a) geográfico: lugar dónde ocurre la conmemoración. b) continuidad: repetición y frecuencia del acontecimiento, y c) organización: quiénes coordinan y promueven las actividades, sean colectivos o instituciones de la ciudad. Las categorías "atribución de movilidad", "atribución de activismo político", "posicionamiento del actor", y "politización" nos permiten comprender cómo el discurso de la acción colectiva de los ciclistas se ha apropiado del lenguaje en las redes sociales digitales.

Entre los hallazgos centrales resaltamos que:

Los días de la semana que presentan mayores porcentajes de publicación de contenidos son: lunes $(19,57 \%)$ y martes $(15,76 \%)$. La mayoría de convocatorias y eventos que realiza CE se concretan los fines de semana, por tal motivo, en los primeros días de la semana entrante, los integrantes del colectivo que publican contenidos en la página, coordinan y organizan la información de los sucesos y acontecimientos de la semana anterior.

La página de CE utiliza como fuente de información a los propios informantes del acontecimiento con un 22,86\%. CE recurre a otras páginas de Facebook para acceder a la información en un 20,0\%. Para CE es más relevante emplear como fuente de información a los activistas del ciclismo urbano 14,29\%. El uso de medios de comunicación digitales como fuente de información alcanza tan solo un 3,57\%.

Dentro de la totalidad de actores a quienes favorecen las publicaciones de Facebook de CE, los cinco principales referentes de posicionamiento positivo son los propios colectivos ciclistas, compañeros del ciclismo urbano en Quito y los principales proyectos de la agrupación: Cicleadas de Velocidad. Los colectivos de ciclistas aprovechan la publicación de contenidos digitales para hablar de sí mismos, y fortalecer los proyectos y acciones colectivas que desarrollan como parte de su activismo de la bicicleta. Igualmente, difunden información sobre sucesos de otros activistas que consideran fundamental para compartir con sus comunidades virtuales.

$\mathrm{CE}$ asume la responsabilidad de los acontecimientos que se comunican por la red social digital Facebook. Uno de los cofundadores de CE, Ricardo Cabascango, es responsable a título personal de la publicación de contenidos. También se visualiza a otro colectivo de la ciudad de Quito que comparte posicionamiento político con CE: Ecuador Cannábico. Si triangulamos tres de las variables (Ricardo Cabascango, Ecuador Cannábico y CE) junto con sus respectivos porcentajes alcanzados, concluimos que existen redes de confianza entre los colectivos que mencionamos, sin contar que Ricardo Cabascango es el vínculo central entre Ecuador Cannábico y CE. Otro detalle importante por señalar, es la responsabilidad que obtiene la página de Facebook Ciclosfera. La página de Cleta endiablada comparte el discurso de las publicaciones de Ciclosfera.

Las principales intencionalidades de las publicaciones de la página de CE son: Promocionar $(24,5 \%)$, Compartir (23,4\%) y Apoyar (17,4\%). Definitivamente las páginas no tienen intencionalidad de Entretener $(1,1 \%)$ o Advertir $(1,1 \%)$. La página de Facebook de CE sustituye el trabajo publicitario que requiere una organización privada o estatal para difundir su ideología y pensamiento. Los propios activistas asignan tiempo, creatividad y tecnología para promocionar y apoyar las acciones colectivas que realizan y concretan en la ciudad. (Ver Tabla 1)

Como resultados de las entrevistas realizadas acotamos que para los integrantes de CE, la apropiación del espacio público se concreta mediante la realización de sus eventos denominados "Cicleadas de velocidad"4. Enrique Marín, cofundador del colectivo argumenta que:

...lo que a mí me gusta y la Cleta tiene como bastante... eso de empoderarse en serio de la calle, de lo que son sus espacios. Porque yo digo, veo por ejemplo, ciclear a otros colectivos, a otras cicleadas, y qué sé yo son... en fila, atrás... atrás... a la derecha cosas así. (Entrevista a Enrique Marín. Quito 28 de abril de 2017, Andrés Rodríguez.)

El proceso de formación y consolidación de CE es un trabajo constante desde el 2014. La agrupación requiere de tres años para arribar al reconocimiento social que manifiesta en el presente año. Acorde a la

\footnotetext{
4 Recorridos en bicicleta por la ciudad de Quito, donde el interés central es recorrer una determinada ruta en el menor tiempo posible. La única disposición general es pedalear por todos los puntos asignados por los participantes. Se hace caso omiso de las normativas de tránsito urbano. No es una competencia. Es una oportunidad para aprender a ciclear dentro de la congestión vehicular de Quito.
} 


\begin{tabular}{|l|r|r|r|r|}
\hline & \multicolumn{5}{|c|}{ Intencionalidad de la publicación } \\
\hline & Frecuencia & Porcentaje & $\begin{array}{c}\text { Porcentaje } \\
\text { válido }\end{array}$ & Porcentaje acumulado \\
\hline Denuncia & 14 & 7,6 & 7,6 & 7,6 \\
Promociona & 45 & 24,5 & 24,5 & 32,1 \\
Critica & 7 & 3,8 & 3,8 & 35,9 \\
Apoya & 43 & 23,4 & 23,4 & 59,2 \\
Ilustra & 17 & 9,2 & 9,2 & 68,5 \\
Comparte & 32 & 17,4 & 17,4 & 85,9 \\
Incide & 19 & 10,3 & 10,3 & 96,2 \\
Entretiene & 2 & 1,1 & 1,1 & 97,3 \\
Advierte & 2 & 1,1 & 1,1 & 98,4 \\
Cólidos & 2 & 1,1 & 1,1 & 99,5 \\
Vende & 1 &, 5 &, 5 & 100,0 \\
Total & 184 & 100,0 & 100,0 & \\
\hline
\end{tabular}

Tabla 1. Datos sobre la intencionalidad de las publicaciones de la página de Facebook de CE al 30 abril de 2016. Elaboración propia a partir de los datos obtenidos con la elaboración de la matriz de contenidos para la Tesis de Maestría “Acción colectiva y redes de comunicación: uso del Facebook en los colectivos ciclistas de Quito".

memoria histórica de otro informante, el concepto de las Cicleadas de velocidad se concibe como:

...una forma urbana, anarquista de ciclear. Es como contra toda ley... contra toda autoridad, y dale solamente pedalea... ese es el objetivo. Hay otros eventos que realizamos también con premios y todo eso... pero estas son de velocidad y no están enfocadas en ganar tampoco, me cachas... es como solo el sentimiento de ir rápido... veloz, de saber lo que puedes lograr, saber que puedes vencer a los autos, saber que puedes acabar con el tráfico, de ver las posibilidades que tienes, del tiempo que puedes hacer. Cruzar la ciudad como la gente no se imagina... o sea, la gente está acostumbrada a ir en bus, piensa que es normal que te cruces Quito en dos horas y no es normal... en bici puedes hacerlo más rápido y es mejor para ti, para el medio ambiente, mejor para casi todos en el mundo. (Entrevista a Gabriel Buitrón. Quito, 4 de mayo de 2017, Andrés Rodríguez)

Las perspectivas colectivas responden a la identidad que define al colectivo ciclista. Nuevos actores sociales ingresan a CE. Con ello, nuevos aportes y formas de activismo se articulan con el pensamiento de los primeros integrantes. En referencia al alcance del activismo de la bicicleta Enrique Marín sostiene que:

...en cuanto a bici... es que verás hay una cosa así, si de hombres ya un filtro, en general... hombres que hacen bici... luego hay un filtro de hombres que hacen bici y salen a la calle... y son ciclistas urbanos... me cachas y luego, hay un filtro... de ahí de los que son activistas... entonces son bien poquitos... lo mismo de las mujeres.

Las conclusiones respecto al grupo focal abordan al ciberactivismo de CE como un modo válido y accesible de protesta en Quito. La lucha social del colectivo la expresa una de sus integrantes como una interacción complicada dentro del ciclismo urbano en Quito:

...hay una cosa que a nosotros como Cleta Endiablada si nos ha costado mucho y es este estigma de que somos unos drogadictos gamines... no... y creo que es una cosa que nos ha costado mucho y que con el Ricky (fundador de CE) hemos hablado alguna veces que no se debe mezclar la una cosa con la otra... aunque muchos de los que somos parte de la Cleta por no decir todos... la gran mayoría sí luchamos también por esta lucha que tenemos por la legalización de la marihuana... sí creo que lo que tenemos que hacer ahorita como colectivos... es buscar la manera que la bici crezca a nivel Quito, a nivel Ecuador, Latinoamérica, sin 
ponernos los pies... porque en realidad todos estamos luchando por lo mismo... solamente que cada uno por su lado... o sea, y hay que saber respetar eso... que si a las Carishinas les gusta hacer de una manera las cosas bacán... si a los de Ciudad en Bici les gusta hacer otra manera... bacán... pero si a la Cleta le gusta hacer de una manera las cosas también bacán y no querer imponer que se manejen de una forma... (Intervención de Diana Arteaga -Cleta Endiablada- en Grupo focal "Uso de Facebook en colectivos ciclistas de Quito" realizado en 25 de mayo de 2017).

CE informa aspectos de la realidad social del ciclismo urbano. Transmiten su posicionamiento político hacia los usuarios de la red social digital y motivan a los actores sociales a empoderarse de la bicicleta como una opción de transporte en Quito. CE manejan sus propios procesos y dinámicas de activismo político.

\section{Ciberactivismo desde la bicicleta y para la legalización del consumo de marihuana}

La asamblea de Cleta Endiablada se concreta el 5 de mayo de 2017 en la Casa Pucará. Lugar de reunión del colectivo donde además funciona un taller permanente de mecánica de bicicleta que lo administran algunos activistas de la agrupación. Este centro cultural, es una casa ocupada e intervenida inicialmente por la organización cultural Diabluma. Antes de la finalización de la asamblea, uno de los integrantes de CE comparte una iniciativa que no formaba parte de la agenda de temas por tratar en esa oportunidad. Es el deseo de participar y viajar al Foro Mundial de la Bicicleta a realizarse en Perú en el año 2018. Dicha manifestación activista la analizamos acorde a la propuesta de Castells acerca del proceso de cambio de la comunicación de masas a la autocomunicación de masas. Recordamos su reflexión sobre ciberactivismo donde considera que el $15 \mathrm{M}$ es un claro reflejo de este proceso en el que, la indignación ciudadana sube a la red donde genera debate e iniciativas, para después volver a las calles y generar interacción entre el espacio urbano y el espacio virtual, que provoca un cambio en las relaciones de poder al influir en las mentes de las personas, que descubren que no se encuentran solas, lo que les hace ser más fuertes y perder el miedo. De esta forma, se pueden encarar las importantes transformaciones de un sistema democrático que hoy en día cada vez se encuentra más alejado de las demandas e intereses ciudadanos (Martín 2013, 146-147)

Pese a que un actor social se involucre directamente con las redes de protesta y crítica que conviven en las acciones colectivas pro bicicleta, se requerirá mucho más que una identificación con el discurso o la repetición de hábitos y lenguajes que caracterizan a las y los ciclistas urbanos para convertir estas dispersas luchas políticas en un movimiento social que tenga la capacidad de transformar la realidad virtual así como la realidad social. El ciberactivismo nació en el Ecuador en el seno de las movilizaciones contra Lucio Gutiérrez, que eran fruto de la iniciativa de una ciudadanía desencantada con los partidos políticos tradicionales, por lo que el "ciberactivismo forajido" no estuvo condicionado por las estrategias de las organizaciones políticas en Internet que tienden a limitar sus capacidades a la propaganda y la búsqueda del voto, lo que le permitió ofrecer a los ecuatorianos, especialmente a los más jóvenes, nuevas formas de organizarse políticamente al margen de los actores tradicionales y de influir en la agenda política. (Martín 2013, 168-169)

Durante el período de análisis de la página de Facebook de CE identificamos tres eventos que evidencian el posicionamiento político y los discursos dominantes en los contenidos publicados. El primero de ellos se denomina "Guatallarin back to the streets". Tiene fecha de realización el 6 de abril de 2017 desde las 19:00 pm hasta las 22:00 pm. El lugar de encuentro es el Parque Julio Andrade. Evento organizado por CE. De acuerdo al registro del evento: 19 perfiles de Facebook asistieron y 27 perfiles mostraron interés en la actividad. Luciana Santillán Comparte un video donde se observa el compromiso que realiza Esteban Almeida, integrante de CE, para compartir con los asistentes a la Cicleada de Velocidad dos blonds ${ }^{5}$ Con todos quienes participen del evento.

El segundo evento se denomina "Cicleada de velocidad - Pedalea al Oriente" La convocatoria se realiza para el 13 de abril de 2017 desde las 19:00 pm hasta las 22:00 pm. El punto de encuentro también es el parque Julio Andrade. Evento organizado por CE. Para esta actividad se registra la asistencia de 26 perfiles de Facebook y el interés por parte de 72 perfiles. Los detalles del evento describen la siguiente información: La Cleta Endiablada tiene el agrado de presentar a la comunidad ciclista esta nueva modalidad de cicleada urbana. Un espacio de velocidad, valentía y precisión en cuál podrás entrenar para los Alleycats ${ }^{6}$ y carreras que se desarrollan en la ciudad. Nivel físico: medio. Tráfico abierto. Todo tipo de bicis. Llevar hidratación. El uso de casco es obligatorio. Evento sólo para mayores de edad. Se recomienda llevar luces o reflectivos. Cada persona asiste y participa bajo su propia responsabilidad.

El último evento que publica CE es la “4:20 \#CicleadaCannábica- 200 años de la Bici”. La actividad se

5 Cigarrillos artesanales de gran proporción que contienen marihuana.

6 Carreras clandestinas e ilegales de ciclismo dentro del perímetro urbano. 
ejecuta el 20 de abril de 2017 desde las 19:00 pm hasta las 22:00 pm. El lugar de reunión es el parque Julio Andrade. En esta ocasión el evento lo organiza CE y Ecuador Cannábico 7 . Según los datos que proporciona su página de Facebook, 197 perfiles de Facebook asisten y a 387 perfiles les interesa el evento. CE describe que por medio de dicha acción colectiva se disfrutará de usar el espacio público, usar la bici y usar el cannabis como métodos de convención cultural, recreación, deporte y salud. Apoyan la iniciativa \#NoMasPresosPorFumar, y argumentan que el espacio público pertenece a todas y todos los ciudadanos. Por ende, publican el siguiente texto: Súmate a esta iniciativa, donde estaremos rodando un pequeño spot de video que muestre a nuestra Comunidad Cannábica activa, empoderada del espacio público. CE comparte tres fotografías donde se muestra la participación de los activistas de la bicicleta para demostrar que son actores y actrices activos de la política y ciudadanía.

Cuando conocemos a las y los activistas de manera personal, y comprendemos sus motivaciones para militar en los colectivos, empezamos a analizar y percibir los contenidos digitales con una perspectiva más humana de la acción colectiva. Una página de Facebook se asemeja al rostro humano. Es imposible ocultar posturas, pensamientos e identificaciones ante las desigualdades sociales.

\section{Conclusiones}

Para encender la llama del activismo digital en primer lugar se requiere encender el computador. El proceso de acción colectiva digital inicia desde el espacio privado de una o un activista. Desde allí se convoca, gestiona y organiza la ejecución de actividades que contribuyan con la movilidad en bicicleta en Quito. No hay que crear nada, pues ya preexiste. Conseguir este espacio no requiere tanto invertir en nuevas infraestructuras específicas como orientar los medios existentes a la disposición de un uso que no tape la diversidad, que no dé alas a la hegemonía de los vehículos motorizados. (Ortega y Martínez 2016, 82)

Acorde a la reflexión teórica que postula que [...] Internet crea un conjunto específico de interacción y no tanto un mero interfaz de vidas sociales "real". En dicho contexto, el recurso a las identidades ocultas, el anonimato, etc. puede representar por sí mismo un camino específico para el desafío del poder y su desestabilización. (Diani y Della Porta 2015, 176) En las páginas de Facebook se identifica, visibiliza y apunta a quienes militan en el activismo de la bicicleta en Quito.

Como señala Castells, la sociedad red es una sociedad global. Pese a ello, las y los activistas de Quito no emulan todas las acciones colectivas referentes al ciclismo urbano que encontramos en las redes sociales digitales. Aunque sean parte de una red de páginas activistas, CE maneja sus propios procesos y dinámicas de activismo político. Podemos identificarla como una agrupación que comparte la siguiente propuesta: como alternativa de movilidad, la bicicleta es adquirida, preparada para el uso y puesta en actividad como medio o conector espacial: permite el desplazamiento de los seres humanos entre distintos puntos de la ciudad. (Bernasconi y Tham 2016, 93)

CE como colectivo de ciclistas no considera que sus integrantes son quienes concretan la acción colectiva que promueve la movilidad en bicicleta en Quito. Sus activistas piensan que son una parte de la acción colectiva porque aun cuando son convocantes o cuando disponen de poder de difusión, entienden que para consolidar una acción colectiva se requiere de otros actores. Como por ejemplo, de quienes no se suben a la bici... de personas que sí se suben a la bici pero no pertenecen ni se identifican con ningún colectivo de ciclistas, e incluso, de personas que practican diversas disciplinas del ciclismo pero no optan por movilizarse en bicicleta por Quito. Si la movilidad en bicicleta aún se concibe como un peligro para la integridad física de quienes optan por esa forma de transporte urbano, significa que las redes sociales continúan difundiendo axiomas y paradigmas donde pedalear por la ciudad es una decisión de pocos y una posibilidad para muchos.

\section{Bibliografía}

Barón Porras, Luis. 2017. Comunicación, lenguajes, TIC e interculturalidad. Cátedra UNESCO de Comunicación. Editado por José Miguel Pereira. Bogotá: Pontificia Universidad Javeriana.

Bennet, Lance. 2007. "Changing Citizenship in the Digital Age" en Civic Life Online: Learning How Digital Media Can Engage Youth. Cambridge: MIT Press.

Bernasconi, Oriana y Maximiliano Tham.2016. "Un enfoque praxiográfico a la bici-movilidad en Santiago de Chile. El ciclismo urbano como un logro colectivo". Revista de Antropología Experimental. 16: 87-110. doi: https://dx.doi.org/10.17561/rae.v0i16.3019

Bravo, Pedro. 2014. Biciosos. ¿Por qué vamos en bici? Y otras preguntas que te haces cuando vas a pedales.

7 Organización social en resistencia frente a la criminalización estatal sistemática de usuarios de sustancias psicoactivas en Ecuador. 
Barcelona: Penguin Random House.

CIESPAL. 2010. "Ciberactivismo de movimientos políticos y sociales en el Ecuador". Informe de estudio 1-150. doi: http://hdl.handle.net/10469/4485

Diani, Mario y Donatella Della Porta. 2015. Los movimientos sociales. Madrid: Centro de Investigaciones Sociológicas: Universidad Complutense.

García Canclini, Néstor. 2007. Lectores, espectadores e internautas. Barcelona: Editorial Gedisa.

Holloway, Sarah y Gill Valentine. 2003. Cyberkids. Niños en la era de la información. Reino Unido: Psychology Press.

Martín, Adolfo Álvaro. 2013. Revoluciones Horizontales. Ciberactivismo y movilizaciones ciudadanas en América Latina y España. San José: FLACSO.

Pérez Rubio, Jairo. 2015. "Ciberactivismo: otra manera de aprender en la solución de problemas sociales". Conferencia pronunciada en el marco de la XXII Cátedra UNESCO de Comunicación, titulada "Comunicación, lenguajes, TIC e interculturalidad: relación entre comunicación, procesos sociales y tecnologías" realizada los días 4,5 y 6 de noviembre del 2015.

Ortega, Diego y Rodrigo Martínez. 2016. "Ciudades a motor y pedales. Apuntes para despejar la confusa selva urbana”. Revista de Antropología Experimental. 5: 71-85. doi: https://dx.doi.org/10.17561/ rae.v0i16.3018

Ortiz, Diego. 2014. “Adolfo Álvaro Martín: 'Ecuador, México y España viven la época del ciberactivismo"”. El Comercio. 4 de febrero. Acceso 27 de octubre de 2017. http://www.elcomercio.com/ tendencias/cultura/adolfo-alvaro-martin-ecuador-mexico.html

Quintana, Yolanda y Mario Tascón. 2012. Ciberactivismo. Las nuevas revoluciones de las multitudes conectadas. Madrid: Catarata.

Rheingold, Howard. 2005. "Mobile Phones, ritual interaction and social capital". The Feature. http://www. thefeaturearchives.com/101545.html

Tarrow, Sidney G. 2012. El poder en movimiento. Los movimientos sociales, la acción colectiva y la política. Madrid: Alianza Editorial.

\section{Manual de Codificación}

Acción colectiva y redes de comunicación: uso del Facebook en los colectivos ciclistas de Quito "Carishina en Bici" y "Cleta Endiablada"

Unidades de análisis:

Publicaciones y comentarios de la página.

Publicaciones y comentarios de visitantes.

Fotos.

Eventos.

Videos.

ID_ Número de la publicación

YEA_Año

\begin{tabular}{|c|c|}
\hline Año & Valor \\
\hline 2015 & 1 \\
\hline 2016 & 2 \\
\hline 2017 & 3 \\
\hline
\end{tabular}


ME_Mes

\begin{tabular}{|l|l|}
\hline \multicolumn{1}{|c|}{ Mes } & \\
\hline Enero & 1 \\
\hline Febrero & 2 \\
\hline Marzo & 3 \\
\hline Abril & 4 \\
\hline Mayo & 5 \\
\hline Junio & 6 \\
\hline Julio & 7 \\
\hline Agosto & 8 \\
\hline Septiembre & 9 \\
\hline Octubre & 10 \\
\hline Noviembre & 11 \\
\hline Diciembre & 12 \\
\hline
\end{tabular}

DI_Día

\begin{tabular}{|l|l|}
\hline \multicolumn{1}{|c|}{ Día } & \\
\hline Lunes & 1 \\
\hline Martes & 2 \\
\hline Miércoles & 3 \\
\hline Jueves & 4 \\
\hline Viernes & 5 \\
\hline Sábado & 6 \\
\hline Domingo & 7 \\
\hline
\end{tabular}

PAG_Tipo de página de Facebook

\begin{tabular}{|l|l|}
\hline 1 & Página de Facebook Carishina en Bici \\
\hline 2 & Página de Facebook Cleta Endiablada \\
\hline
\end{tabular}

CON_Tipo de contenido

\begin{tabular}{|l|l|}
\hline 1 & Publicación de la página \\
\hline 2 & Comentario de la página \\
\hline 3 & Publicación de visitante \\
\hline 4 & Comentario de visitante \\
\hline 5 & Foto \\
\hline 6 & Evento \\
\hline 7 & Video \\
\hline
\end{tabular}

TEM_Tema (para medir actualidad): dimensión desde la que se aborda el concepto teórico de acción colectiva.

\begin{tabular}{|l|l|}
\hline 1 & Participación en medios de comunicación \\
\hline 2 & $\begin{array}{l}\text { Foros de movilidad en bicicleta interna- } \\
\text { cionales }\end{array}$ \\
\hline
\end{tabular}




\begin{tabular}{|c|c|}
\hline 3 & Intervención en el espacio público \\
\hline 4 & Semana de la Movilidad en Quito \\
\hline 5 & Emprendimientos sociales del ciclismo \\
\hline 6 & $\begin{array}{l}\text { Emprendimientos económicos del ciclis- } \\
\text { mo }\end{array}$ \\
\hline 7 & Turismo en bicicleta \\
\hline 8 & Proyectos del colectivo \\
\hline 9 & Talleres de mecánica para bicicleta \\
\hline 10 & Fiestas y festividades \\
\hline 11 & Historias de deportistas \\
\hline 12 & Carreras urbanas y Alleycats en Quito \\
\hline 13 & Cicleada mensual "Masa crítica" \\
\hline 14 & Reuniones y asambleas \\
\hline 15 & Interacción con otros colectivos sociales \\
\hline 16 & Cicleadas urbanas \\
\hline 17 & Enseñanza del manejo de la bicicleta \\
\hline 18 & Accidentes de ciclistas urbanos \\
\hline 19 & Muerte de ciclistas urbanos \\
\hline 20 & Acoso callejero \\
\hline 21 & Desigualdad de género \\
\hline 22 & Rutas y senderos fuera de la ciudad \\
\hline 23 & $\begin{array}{l}\text { Proyectos de otros colectivos ciclistas de } \\
\text { Quito }\end{array}$ \\
\hline 24 & Historia del ciclismo urbano \\
\hline 25 & Consejos para ciclear en la ciudad \\
\hline 26 & Robo de bicicletas \\
\hline 27 & Políticas públicas de movilidad urbana \\
\hline 28 & $\begin{array}{l}\text { Carreras urbanas y Alleycats internaciona- } \\
\text { les }\end{array}$ \\
\hline 29 & $\begin{array}{l}\text { Difusión de productos comunicacionales } \\
\text { sobre ciclismo urbano }\end{array}$ \\
\hline 30 & Red de ciclovías en Quito \\
\hline 31 & Ciclopaseo semanal Quito \\
\hline 32 & $\begin{array}{l}\text { Sistema de alquiler de bicicleta Pública } \\
\text { (Bici Quito) }\end{array}$ \\
\hline 33 & $\begin{array}{l}\text { Proceso de adquisición de bicicletas eléc- } \\
\text { tricas }\end{array}$ \\
\hline 34 & $\begin{array}{l}\text { Denuncias ante el Municipio del Distrito } \\
\text { Metropolitano de Quito (MDMQ) }\end{array}$ \\
\hline 35 & $\begin{array}{l}\text { Denuncias para la Agencia Nacional de } \\
\text { Tránsito (ANT) }\end{array}$ \\
\hline 36 & Venta de bicicletas y accesorios \\
\hline 99 & Otros \\
\hline
\end{tabular}


7. OT_Otros: cuál:

ZO_Zona (para medir proximidad geográfica): lugar donde se centra la publicación: país, provincia, cantón, parroquia, comunidad, o avenida.

\begin{tabular}{|l|l|}
\hline 1 & Ecuador \\
\hline 2 & Provincia \\
\hline 3 & Cantón \\
\hline 4 & Comunidad \\
\hline 5 & Calle, avenida \\
\hline 6 & Internacional \\
\hline 98 & Ninguno o no se expresa \\
\hline 99 & Otros \\
\hline
\end{tabular}

9. OT2_Otros: cuál

PER_Personalización: Protagonista de la publicación

\begin{tabular}{|c|c|}
\hline 1 & Augusto Barrera ex Alcalde de Quito \\
\hline 2 & Mauricio Rodas Alcalde actual de Quito \\
\hline 3 & $\begin{array}{l}\text { Usuarios del Sistema de Bicicleta Pública } \\
\text {-BiciQuito- }\end{array}$ \\
\hline 4 & Ciclistas urbanos de Quito \\
\hline 5 & $\begin{array}{l}\text { Ciclistas urbanos de otras provincias del } \\
\text { Ecuador }\end{array}$ \\
\hline 6 & Ciclistas urbanos internacionales \\
\hline 7 & Colectivos ciclistas de Quito \\
\hline 8 & $\begin{array}{l}\text { Colectivos ciclistas de otras provincias del } \\
\text { Ecuador }\end{array}$ \\
\hline 9 & Colectivos ciclistas internacionales \\
\hline 10 & $\begin{array}{l}\text { Organizaciones no gubernamentales que } \\
\text { trabajen en temas de ciclismo }\end{array}$ \\
\hline 11 & Secretaría de Movilidad de Quito \\
\hline 12 & Peatones \\
\hline 13 & Conductores de vehículos motorizados \\
\hline 14 & Usuarios de transporte público \\
\hline 15 & Activistas del propio colectivo \\
\hline 16 & Medios de comunicación \\
\hline 17 & $\begin{array}{l}\text { Usuarios de otros medios de transporte no } \\
\text { motorizado }\end{array}$ \\
\hline 18 & $\begin{array}{l}\text { Conductores de vehículos de transporte } \\
\text { público }\end{array}$ \\
\hline 19 & $\begin{array}{l}\text { Conductores de vehículos de transporte } \\
\text { privado }\end{array}$ \\
\hline 20 & Ciclistas de élite \\
\hline 21 & Agentes de Tránsito \\
\hline 22 & Importadores de bicicletas y accesorios \\
\hline
\end{tabular}




\begin{tabular}{|l|l|}
\hline 23 & Policía Nacional \\
\hline 24 & Auspiciantes de eventos del colectivo \\
\hline 98 & Ninguno \\
\hline 99 & Otros \\
\hline
\end{tabular}

OT3_Otros: cuál

ATR_MOV_Atribución de movilidad ¿Aparece representado como un actor que promueve la movilidad en bicicleta?

\begin{tabular}{|l|l|}
\hline Atributo & Valor \\
\hline Sí & 1 \\
\hline No & 2 \\
\hline No aplica & 3 \\
\hline
\end{tabular}

ATR_ACT_Atribución de activismo político ¿Aparece representado como un actor que participa del activismo político?

\begin{tabular}{|l|l|}
\hline Atributo & Valor \\
\hline Sí & 1 \\
\hline No & 2 \\
\hline No aplica & 3 \\
\hline
\end{tabular}

TON_Tono general de la publicación: el tono de la publicación es

\begin{tabular}{|l|l|}
\hline 1 & Positivo \\
\hline 2 & Negativo \\
\hline 3 & Neutro \\
\hline
\end{tabular}

SOR_Sorpresa: ¿la publicación o el contenido agrega tono o matices que enfatizan el carácter sorpresivo de la publicación?

\begin{tabular}{|l|l|}
\hline 1 & Sí \\
\hline 2 & No \\
\hline 3 & Neutro o no aplica \\
\hline
\end{tabular}

IMA_SOR_Sorpresa: ¿incorpora imágenes y/o videos que respaldan o aumentan el carácter sorpresivo de la publicación?

\begin{tabular}{|l|l|}
\hline 1 & Sí -imagen sorpresiva \\
\hline 2 & No -imagen no sorpresiva \\
\hline 3 & Neutro- imagen neutra \\
\hline 4 & No imagen \\
\hline
\end{tabular}

INT_Intencionalidad: ¿Cuál es la intención que expresa la publicación o el contenido de la publicación? 


\begin{tabular}{|l|l|}
\hline 1 & Denuncia \\
\hline 2 & Promociona \\
\hline 3 & Critica \\
\hline 4 & Apoya \\
\hline 5 & Ilustra \\
\hline 6 & Comparte \\
\hline 7 & Incide \\
\hline 98 & Ninguna \\
\hline 99 & Otra \\
\hline
\end{tabular}

18. OT4_Otras: cuál

IMA_INT_Intencionalidad: ¿incorpora imágenes y/o videos que respaldan o aumentan la intencionalidad de la publicación?

\begin{tabular}{|l|l|}
\hline 1 & Sí -imagen intencional \\
\hline 2 & No -imagen no intencional \\
\hline 3 & Neutro- imagen neutra \\
\hline 4 & No imagen \\
\hline
\end{tabular}

POL_Politización: ¿la publicación o el contenido agrega tono o matices que enfatizan el carácter político de la publicación?

\begin{tabular}{|l|l|}
\hline 1 & Sí \\
\hline 2 & No \\
\hline 3 & Neutro o no aplica \\
\hline
\end{tabular}

IMA_POL_Politización: ¿incorpora imágenes y/o videos que respaldan o aumentan el carácter político de la publicación?

\begin{tabular}{|l|l|}
\hline 1 & Sí -imagen política \\
\hline 2 & No -imagen no política \\
\hline 3 & Neutro- imagen neutra \\
\hline 4 & No imagen \\
\hline
\end{tabular}

FU_Fuentes utilizadas: ¿qué tipo de fuentes se han utilizado?

\begin{tabular}{|l|l|}
\hline 1 & Informantes del acontecimiento \\
\hline 2 & Expertos en estudios urbanos \\
\hline 3 & Expertos en políticas públicas \\
\hline 4 & Actores políticos del Municipio de Quito \\
\hline 5 & $\begin{array}{l}\text { Actores políticos de otras instituciones } \\
\text { administrativas }\end{array}$ \\
\hline 6 & Actores del tránsito urbano \\
\hline 7 & Agentes Nacionales de Tránsito \\
\hline
\end{tabular}




\begin{tabular}{|l|l|}
\hline 8 & Medios de comunicación digitales \\
\hline 9 & Blogs personales o políticos \\
\hline 10 & $\begin{array}{l}\text { Fuentes documentales, informes... oficia- } \\
\text { les }\end{array}$ \\
\hline 11 & $\begin{array}{l}\text { Fuentes documentales, informes... no ofi- } \\
\text { ciales }\end{array}$ \\
\hline 12 & Normativa legal \\
\hline 13 & Investigaciones académicas \\
\hline 14 & Páginas de Facebook \\
\hline 15 & Cuentas de Twitter \\
\hline 16 & Productoras audiovisuales \\
\hline 17 & Activistas del ciclismo urbano \\
\hline 97 & Varias de las anteriores \\
\hline 98 & No se citan fuentes \\
\hline 99 & Otras \\
\hline & \\
\hline
\end{tabular}

23. OT5_Otras: cuál

RES_ ¿Existe una asignación de responsabilidad de lo acontecido?

\begin{tabular}{|l|l|}
\hline 1 & Sí \\
\hline 2 & No \\
\hline 3 & Neutro o no aplica \\
\hline
\end{tabular}

ASIG_RES_En caso de que exista asignación de responsabilidad, ¿quién es?-

POS_Posicionamiento: ¿apoya o desfavorece a algún actor?

\begin{tabular}{|l|l|}
\hline 1 & Favorable al colectivo ciclista en estudio \\
\hline 2 & $\begin{array}{l}\text { Desfavorable al colectivo ciclista en estu- } \\
\text { dio }\end{array}$ \\
\hline 3 & $\begin{array}{l}\text { Favorable a instituciones públicas relacio- } \\
\text { nadas con la movilidad en bicicleta }\end{array}$ \\
\hline 4 & $\begin{array}{l}\text { Desfavorable a instituciones públicas rela- } \\
\text { cionadas con la movilidad en bicicleta }\end{array}$ \\
\hline 5 & $\begin{array}{l}\text { Favorable a otros actores de la movilidad } \\
\text { urbana }\end{array}$ \\
\hline 6 & $\begin{array}{l}\text { Desfavorable a otros actores de la movili- } \\
\text { dad urbana }\end{array}$ \\
\hline 7 & Neutro \\
\hline 8 & No aplica \\
\hline 99 & Otros \\
\hline
\end{tabular}

OT6_Otros: cuál

27.ASIG_POS_A quién desfav/fav 
HAS_Hashtags utilizados en la publicación

COMP_N ${ }^{\circ}$ de compartidos de la publicación

GUS_No de Me gusta

VIN_Vinculación: ¿Incluye enlace a noticia o a otra página de Facebook?:

\begin{tabular}{|l|l|}
\hline 1 & Sí \\
\hline 2 & No \\
\hline
\end{tabular}

8005 